\title{
Pre-existence of cacao pod borer (Carmenta foraseminis (Busck) Eichlin) in dry tropical living environments
}

\section{Introduction}

The Cacao Pod Borer (Carmenta foraseminis (Busck)) Eichlin, is a moth with transparent wings (Figure 1), family Sesiidae, whose larvae drill cacao pods to complete their life cycle inside them. Upon emerging from the fruits, adults leave exit holes open through which moisture and biological agents enter that compromise the commercial value of the grains.

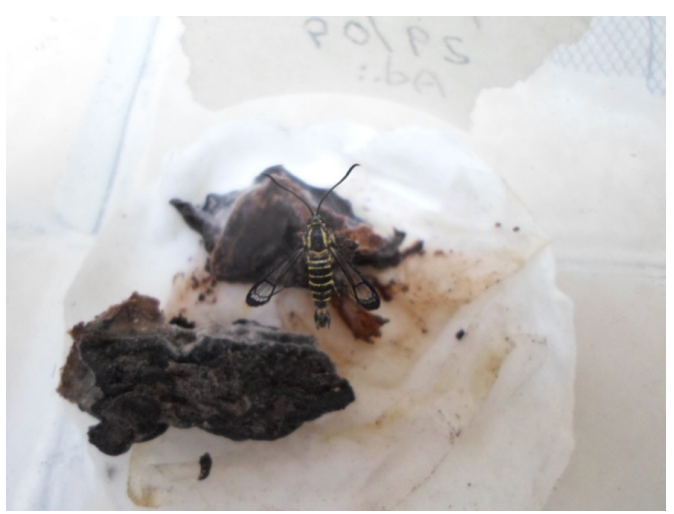

Figure I Adult of Cacao Pod Borer just emerged from a piece of fruit.

In Colombia, the Cacao Pod Borer has been reported in the West and Southwest of the department of Antioquia, in some municipalities of the department of Cundinamarca, Tolima and Norte de Santander but yet is not registered in other important producer departments like Santander del Sur, Arauca, Meta and Huila.

The reason for the presence of the Cacao Pod Borer in remote places where cacao is grown is a matter of discussion. The content of this manuscript is a thesis on observations made in one of these places.

\section{Observations on cacao pod borer in a cacao farm}

The Cacao Pod Borer, Carmenta foraseminis (Busk) Eichlin, was recorded its presence in the year 2011 at La Virgencita farm, place named Tabacal, municipality of Buriticá (department of Antioquia, Colombia), of a dry tropical environment, in a cacao plantation 4 years old, just started its production. In August 2014, three years later, the plantation was again inspected and found a high infestation of the insect to the point of obtaining 6 adults emerged from a single fruit as can be seen in Figure 2,3.

This premise leads us to think that the insect was part of the diversity insects of the ecosystem, and, as a consequence, was a preexisting pest before establishing the cacao. As the cultivation grew in age and increased its production, the population of the Pod Borer went augmenting until reaching the levels recorded in the last inspection of the year 2014
Volume 6 Issue I - 2022

\section{Gabriel Cubillos \\ Agronomist Engineer}

Correspondence: Gabriel Cubillos, Agronomist Engineer Carrera 86 \#34-56, Medellín, Colombia, Email cubillos.g@gmail com

Received: January 31, 2022 | Published: February 08, 2022

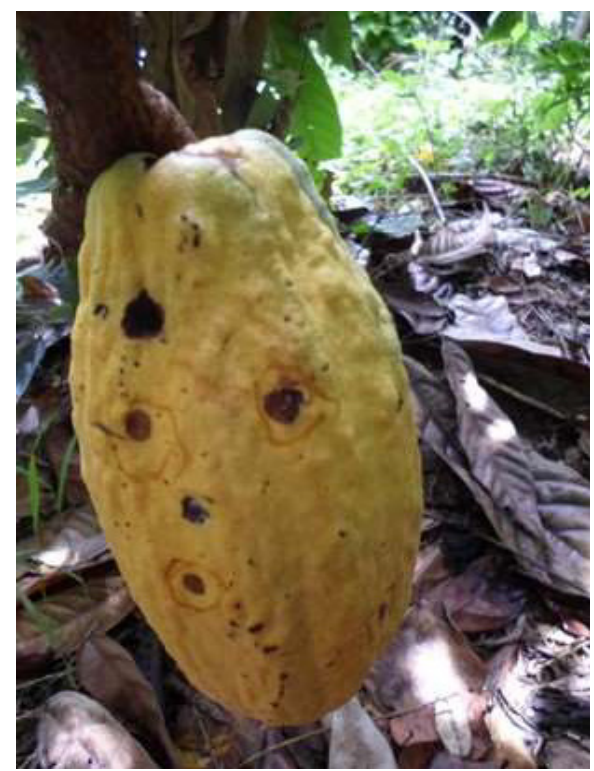

Figure 2 Freckles indicative of presence of Cacao Pod Borer in a cacao fruit. 


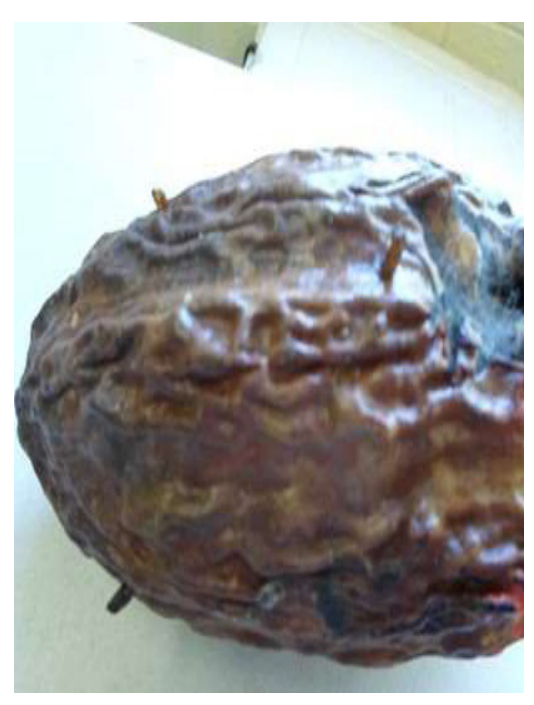

Figure 3 Pupal exuviae left by adults after its emergence.

The same could happen with the outbreaks of the pest in municipalities from Tolima, Cundinamarca, Boyacá, Norte de Santander, Caquetá, Cauca, Caldas, Risaralda and Nariño (Jaime Mujica, 2015 personal information) where it emerged from a moment to another causing severe crop damage apparently without any connection to previously infested areas.
It is presumed, then, the pre-existence of the Cacao Pod Borer, especially in some regions under dry tropical conditions, where an attractive host favors the multiplication of its population thus causing significant damage to cacao harvests.

Consequently, monitoring should be undertaken to determine its presence in the different production areas, recognize their native hosts, incidence and losses values and study control measures adjusted to the seasons of harvest from the different regions with chemical molecules (insecticides) and/or biological enemies properly tested to prevent the Cacao Pod Borer becomes another depressing factor of the cacao production in Colombia.

\section{Acknowledgments}

None.

\section{Conflicts of interest}

The author declares there is no conflict of interest.

\section{References}

1. Cubillos G. The Cocoa Pod Borer, Carmenta foraseminis (Busck) Eichlin: observations about life cycle stages and emergence index adults. News of the Lepidopterist's Society. 2016;58(2):72-75. 